\title{
MaVericks, Visionaries, Protectors, and SageS: TOWARD A TYPOLOGY OF COGNITIVE STRUCTURE FOR DECISION MAKING IN ORGANIZATIONS
}

\author{
Dennis Duchon \\ Donde P. Ashmos \\ Maria Nathan \\ University of Texas at San Antonio \\ San Antonio, TX
}

\begin{abstract}
This paper reports a study of the relationship between cognitive structure and organizational decision making. Cognitive structure, a framework that helps the decision maker organize and interpret information, has both context (conventional vs. non-conventional) and process (conclusive vs. nonconclusive) dimensions. Based upon context and process combinations, four cognitive structures are identified. Results indicate systematic relationships between cognitive structure and both the perception of a problem and the choices made. The four types can be seen as mutually supportive, each contributing special strengths to decision making in organizations.
\end{abstract}

\section{Introduction}

Decision making in organizations often involves multiple players, who bring to the task varying frames of reference and interpretation skills. In the case of strategic decisions, for example, the actors engage in choice making about how to align a company's competencies with the opportunities and threats in its environment. Yet before any kind of alignment can take place, the nature of competencies, opportunities, and threats must be identified, understood, and articulated by the decision maker or decision making group. Each individual decision maker mentally observes and organizes data in a way that gives meaning to these variables. To do this each decision maker conceptualizes these variables in a mental framework that makes sense and which enables the interpretation of organizational issues and strategic choice making (Janis, 1982). Most decision making in organizations depends on the compilation of objective data, but the interpretation of these data is influenced by decision makers' cognitions (Bateman \& Zeithaml, 1989; Anderson \& Payne, 1975; Das, 1986; Mitchell, Rediker \& Beach, 1986; Weick, 1995; 1979). Thus, human cognitive and psychological processes (Bateman 
\& Zeithaml, 1989; Eisenhardt \& Zbaracki, 1992) are important factors which influence organizational decision making.

Cognitive psychologists have established that individuals use conceptual frameworks, sometimes called cognitive structures or schemas (Hogarth, 1980), to organize beliefs and preferences which influence decisions. In this paper we suggest that the cognitive structures of decision makers differ on two dimensions: preference for context and preference for process. Grounded in Hogarth's (1980) view of schemas as including an acquisition component (i.e., how information is acquired) and a processing component (i.e., how information is processed), we combine dimensions of context and process and create four characteristic cognitive structures in order to examine whether or not some combination of these mental structures helps explain decision makers' interpretations and choices. An examination of 123 decision makers indicates that differences in cognitive structures, in fact, are associated with different interpretations of strategic issues and different choices (cf., Gioia \& Mehra, 1996). Based on our results we identify implications of having multiple cognitive structures represented in decision making in organizations.

\section{Cognitive Structure}

The choices that organizations make and the outcomes of those choices are reflections of the cognitive structures of top level decision makers (Hambrick \& Mason, 1984). These cognitive structures are a powerful influence on decision making in an organization. Janis (1989), for example, suggests that individual cognitive structures significantly constrain organizational problem solving. Nystrom \& Starbuck (1984) go even further by arguing that organizational crises are most often created by the manager's thinking processes rather than external events. Thus, in order to better understand how decisions are made in organizations, we must know something about the cognitive structures that guide and shape perception and choice.

Decision makers use mental frameworks to organize information in ways that enable them to understand decision issues and to make choices (Hall, 1984; Hogarth, 1980; Schoemaker, 1993). These frameworks are the "networks of ideas that people possess mentally when they confront their world" (Cowan, 1987). Such frameworks, sometimes referred to as cognitive structures, and sometimes referred to as schemas (Hogarth, 1980; Ireland, Hitt, Bettis, \& dePorras, 1987), characterize a person's experience and beliefs about a task environment (Hogarth, 1980). Cognitive structures are constructed from past experiences (Kiesler \& Sproull, 1982) and enable individuals to perceive, remember, infer, and evaluate. In choice situations, cognitive structures impart meaning (Gioia \& Poole, 1984) and allow managers to categorize events, assess consequences, and consider appropriate actions in a timely and efficient manner (Ireland et. al., 1987). 
Hogarth (1980) argues that cognitive structures or schemas can be decomposed into two operations: acquisition of information and processing of information. These operations lead to choices. Thus, a person's schema or cognitive structure, is expressed or reflected by the nature of information that is acquired (e.g., where it comes from, what type it is) and by the way the information is processed (i.e., what mental operations are applied to the information). Hogarth's framework provides the basis for the conceptualization we offer in this paper (See Figure 1). We argue that decision makers, because of differences in cognitive structures, differ in their preferences for types of information and differ in their preferences regarding information processing. That is, the cognitive structure predisposes or prepares the decision maker to form certain kinds of perceptions (information acquisition) and make certain kinds of choices (information processing).

\section{Preference For Context}

Hogarth (1980) argues that judgment is a function of two operations: acquisition of information and processing of information. In order for decision makers to make choices, they select information they believe salient to the task and they then adopt a processing strategy. Russo and Schoemaker (1990) argue that individuals develop preferences for both the types of information they select and the processing style they use. These preferences constitute a personal frame or structure which, over time, proves useful and familiar. In this study, we describe cognitive structure in terms of two dimensions. We refer to the preference for acquiring a particular type of information as the "context" dimension because the type of information selected creates a context for processing and choice. We refer to the preference for using information as the "process" dimension of cognitive structure.

The context dimension reflects the decision maker's preference for a particular type of information which derives from a consistent source. Hogarth suggests that an individual's memory is a major source of information. Memory, in turn, is a function of the individual and as individuals differ in what information they select from memory to be relevant to a given task, they construct different contexts which can lead ultimately to different choices.

Thus, a decision maker's cognitive structure leads him/her to familiar information in order to reduce uncertainty in choice situations. In uncertain choice situations, there will not be an obvious or "rational" source of information. Therefore, the decision maker retreats to an information source that is comfortable, familiar and has proven useful in past episodes. This fall back position is a preference and functions as a reference point. For example, in an uncertain situation a decision maker might characteristically use history or tradition as the preferred context or source of information (March, 1981; Mitchell et. al., 1986). Alternatively, the decision maker may characteristically reject tradition and seek out a source of information which contravenes conventional wisdom. In either case, however, the choice of what information to acquire via a preferred 
context is rooted in the decision maker. Building on the work of Kirton (1976) and Myers (1962) we propose that it is useful to think of the context dimension as being characterized by a preference for information which is anchored in either a conventional or non-conventional context.

CONVENTIONAL CONTEXT. The conventional context is a preference for current paradigms, accepted practice, or standard procedures. Thus, the primary source of information needed for decision making within this context is tradition or history. In the conventional context, decision makers accept things the way they are and look to historical practices for clues in dealing with current issues. In relying on the conventional context, decision makers might be on the lookout for improvements, but these improvements will take the form of modifications of current practice, or the achievement of greater efficiency by "tinkering." Such an incremental approach results from an information source preference for tried and true practices. The conventional context represents a cognitive structure which guides the decision maker within the domain of what is known.

NON-CONVENTIONAL CONTEXT. The non-conventional context, in contrast, is a preference for new or alternative paradigms and untried ideas. Thus, the primary source of information needed for decision making lies outside current ways of thinking, the existing system and its traditions. In the non-conventional context, decision makers do not look to historical patterns as the major source of information. Rather, they seek improvements by challenging accepted practice and ignoring the existing system. Such an approach is undertaken because the major source of preferred information lies outside the existing system and outside history and tradition. The non-conventional context expresses a cognitive structure which guides the decision maker's information search outside the domain of what is known.

\section{Preference For Process}

In addition to the context dimension (which can be thought of as providing an anchor or reference point), there is also a process dimension that reflects the decision maker's preference for seeking closure or continuing to acquire information (Hogarth, 1980). Current views of information processing are grounded in Simon's (1978) descriptions of the limits of human information processing. Due to cognitive limitations, decision makers do not use exhaustive search and evaluation processes. Rather than trying to cope with enormous information demands, decision makers attempt to constrain the decision problem and then seek a satisfactory (rather than optimal) solution to that problem.

Taylor (1984) refers to the constraint pressures on cognitive processes as "cognitive strain" (p. 80) and suggests, as others have (cf. Tversky \& Kahneman, 1974) that decision makers typically deal with cognitive strain by developing simple heuristics or rules-of-thumb. What is important for the current study, however, is Taylor's (1984) claim that decision makers vary in their ability to cope with cognitive strain. The cognitive characteristics of 
decision makers influence information handling and exert a major influence on idiosyncratic decision making behaviors such as whether or not to search for more information (p. 101).

Others have also noted individual differences in a preference for a satisfactory "amount" of information processing. Harrison (1981), for example, notes that information search activity persists as long as acceptable standards are not obtained. The acceptability of standards varies among decision makers because the search for alternatives is mediated by human preferences. Huber (1980) argues that in the decision making stage of generating alternatives some people will slight the alternative-generation process in favor of proceeding to evaluation and choice, and that this has the effect of reducing the opportunity for high quality solutions to be identified.

Thus, individuals have a process preference, in particular, a preference for the amount of information processing they will undertake. MacCrimmon and Wehrung (1986), in a large-scale study of managerial decision making and risk taking, note individual differences in information processing by observing that some managers have a propensity to gather more information and others have a propensity to decide based on the information already at hand. Interestingly, the managers who delayed making choices by gathering more information tended also to be risk-averse.

In this paper, we focus on the preference of the decision maker to act on information or to search for more. The information acquired is used either to make a judgment or as the springboard for further information gathering. Thus, we propose that it is useful to think of the process dimension as being characterized by a preference for either a conclusive or nonconclusive process.

CONCLUSIVE PROCESS. This process expresses a preference for using information to make a judgment and to reach closure. Decision makers who use a conclusive process are trying to settle things, finalize and categorize through procedures that are definite although reasonable and rational. A preference for conclusive processes is accompanied by a preference for planning and following plans. A conclusive process is orderly and fast.

NONCONCLUSIVE PROCESS. This process expresses a preference for knowing more and using the information at hand to determine what additional information is needed. It is a process used to find out more - acquire or develop more information and thus delay closure. Decision makers who use a nonconclusive process are trying to stay open to other (new) possibilities and they resist finalizing or concluding. A preference for a non conclusive process is most likely not orderly and may be slow.

\section{Four Cognitive Structure Categories}

By combining the context and process dimensions we can propose four characteristic cognitive structures. We have labeled each combination and describe them below. See Figure 1 for a summary description of the four categories. 
Figure 1

Cognitive Structures

Preference for Process

(Information Processing)

Nonconclusive

Conclusive

\begin{tabular}{|c|l|l|}
\cline { 2 - 3 } \multicolumn{1}{c|}{ Conventional } & $\begin{array}{l}\text { Current paradigms } \\
\text { Accepted practice } \\
\text { Standard procedures } \\
\text { Discover more } \\
\text { Delay deciding } \\
\text { Stay open to possibilities } \\
\begin{array}{c}\text { Preference for } \\
\text { Context } \\
\text { (Information } \\
\text { Acquisition) }\end{array}\end{array}$ & $\begin{array}{l}\text { Current paradigms } \\
\text { Accepted practice } \\
\text { Standard procedures }\end{array}$ \\
Sage & $\begin{array}{l}\text { Sake judgement } \\
\text { Finalize }\end{array}$ \\
Non-conventional & Protector \\
\hline $\begin{array}{l}\text { Outside current paradigms } \\
\text { Challenge current practice } \\
\text { Ignore existing system's } \\
\text { current paradigms }\end{array}$ & $\begin{array}{l}\text { Outside current paradigms } \\
\text { Challenge current practice } \\
\text { Ignore existing system's } \\
\text { current paradigms } \\
\text { Delay deciding } \\
\text { Stay open to possibilities } \\
\text { Visionary }\end{array}$ & $\begin{array}{l}\text { Seek closure } \\
\text { Make judgement } \\
\text { Finalize }\end{array}$ \\
\hline
\end{tabular}

PROTECTOR. The Protector structure prefers a conventional context and a conclusive process. Thus, the Protector seeks information within the existing domain, prefers order and acts decisively. In organizational decision making, the Protector relies on tradition as a source of information for what the organization should do next and seeks to use the information to act, decide or reach closure. Protectors might seek small variations in current practice in order to achieve greater efficiencies and then actively pursue those small changes.

SAGE. The Sage structure prefers a conventional context and a nonconclusive process. Thus, the Sage looks to past practice and the existing system for information needed to interpret events, yet feels little necessity to move towards closure. Tradition and history provide the major sources of critical information needed for organizational decision making, however the cognitive structure differs from that of the Pro- 
tector because the Sage rejects process boundaries, preferring to use existing information to search for new problem solutions. The Sage structure may create conflict for a decision maker who gets caught between the rigors of standard procedures and curiosity about alternatives. The Sage functions as a caretaker, conventional but distant, seeing to it that history and tradition provide the decision making anchor, yet finding it unnecessary to move towards closure quickly.

MAVERICK. The Maverick structure prefers a nontraditional context and a conclusive process. Thus, the Maverick rejects existing paradigms, looks for information beyond the established order, and is intentional and decisive in making choices. The major source of critical information needed for organizational decision makers is in new ideas and alternate frameworks. The Maverick prefers nontraditional sources of information but then seeks to act on the newly acquired information. The Maverick will assert the need for paradigm shifts, and will relentlessly make the choices to effect that shift. The Maverick prefers to lay the new framework on existing problems, then decide and move on.

VISIONARY. The Visionary structure prefers a nontraditional context and nonconclusive processes. Thus, the Visionary structure relies on information outside the established order and is also open to alternative ways of using that information. The Visionary constantly seeks to know more. The Visionary appears hesitant because s/he avoids a final decision. The Visionary may be able to articulate a new direction for an organization, but may lack the decisiveness to chart the course and implement that direction. The Visionary could be viewed as an eccentric - someone who is out of touch.

Differences in cognitive structure (i.e., preferences for context and process) will lead to systematic differences not only in the ways decision problems are perceived, but also in the decisions that are made. While there are many ways to capture perceptions of decision problems, in the current study, we have operationalized perception in terms of the degree of risk seen in a decision problem. While perception of risk does not capture the entire problem space, it does capture an important element which can be "seen" different ways by different people. We believe that differing perceptions of risk will in turn be associated with different behaviors. Thus, based upon the discussion above, we make the following predictions:

Hypothesis 1. Decision makers characterized by a preference for a conventional context (Sages and Protectors) will perceive more risk in a given decision situation than will decision makers characterized by a preference for non-conventional context (Mavericks and Visionaries).

That is, cognitive structures which prefer conventional practice will perceive risk in something outside conventional practice, while cognitive structures which prefer non-conventional practice will not. 
Hypothesis 2: Decision makers characterized by a preference for a conventional context (Protectors and Sages) will make choices that are more risk averse than will decision makers characterized by a preference for non-conventional context (Mavericks and Visionaries).

That is, cognitive structures which prefer conventional practice will make choices in support of conventional practice, while cognitive structures which prefer nonconventional practice will not.

Hypothesis 3. Decision makers characterized by a preference for nonconclusive process (Sages and Visionaries) will perceive more risk in a given situation than will decision makers characterized by conclusive processes (Protectors and Mavericks).

We expect this outcome because the nonconclusive cognitive structure does not seek closure and will find it risky to commit to an alternative. The conclusive cognitive structure, on the other hand, seeks closure and will not necessarily perceive commitment to a choice as a risk.

Hypothesis 4: Decision makers characterized by a preference for nonconclusive process (Sages and Visionaries) will make choices that are more risk averse than will decision makers characterized by a preference for conclusive processes (Protectors and Mavericks).

Again, the nonconclusive cognitive structure seems risk averse because it prefers not choosing.

\section{Method}

The present study is an experiment in which decision makers assessed the amount of risk involved in a decision (an act of interpretation) and then made a choice. Decision makers were classified according to their characteristic or preferred cognitive structure. We then examined how these different cognitive structures might be associated with different interpretations of risk and different decision outcomes.

The sample consisted of 123 employees from an international, high-technology engineering firm: $70 \%$ males, $30 \%$ females, average age 33.9 years. These people have, on average, been with the company 5.5 years, and in their present jobs 3.9 years. Approximately $27 \%$ of the sample have some college, $9 \%$ graduated from a technical school, 30\% have bachelor's degrees, 31\% have master's degrees and 3\% hold a Ph.D. (There are six employees for whom educational data are missing.) 


\section{Procedure}

Subjects were administered a questionnaire that measured each decision maker's characteristic cognitive structure. Subjects also read a scenario describing a strategic decision making situation involving a proposed corporate joint venture with a competitor and responded to questions about their perceptions and choices.

In order to make the scenario as realistic as possible, it was designed with the help of representative managers not included in the study. A strategic decision situation was devised that these managers felt was both realistic and possible. In addition, language and procedures idiosyncratic to the firm were incorporated to ensure subject familiarity with, as well as interest in, the situation being described. See Appendix A for details of the scenario. Note that in terms of expected value (i.e., given the probabilities and other information in the scenario), the "best" choice is accepting the joint venture. Refusing the joint venture is a riskier alternative. Thus, the conventional choice is to accept the joint venture.

\section{Independent Variable}

The independent variable in this study was cognitive structure. Cognitive structure can manifest itself in both the interpretational and choice making stages of decision making. We assessed two dimensions of cognitive structure: preference for context and preference for process.

Context Measure. Cognitive context was measured with the Kirton AdaptationInnovation Inventory (KAI) (Kirton, 1976). The KAI is an assessment of cognitive structure based upon the assumption that individuals can be located on a continuum ranging from a predisposition to "doing things better" (Adaptor) to a predisposition to "doing things differently" (Innovator). These anchor points are equivalent to our descriptions of Conventional and Non-conventional contexts. The Conventional context consists of tried and true methods to solve problems, and concerns itself with problem solutions that will be efficient, precise, and reliable. Individuals who prefer the Conventional context seek stability, order and continuity.

People whose style is to do things differently are said to prefer a Non-conventional (Innovator) context. The Non-conventional context does not consist of tried and true approaches to problems. Rather it is characterized by tangential thinking and novel approaches to problems, approaches outside the accepted system. The Nonconventional context does not rely on customary procedures.

The original KAI (Kirton, 1976) was composed of 32 items. Based on psychometric work conducted by Keller and Holland (1978a, 1978b, 1979), the present study used a 13-item version of the original instrument. The instrument requires subjects to imagine presenting a certain image of themselves to others. They are then asked to rate the difficulty of presenting such an image for each of the traits or attributes stated in the 13 items. Responses to the items were indicated on a 5 point scale which was anchored by "very easy" and "very difficult." The scale was scored such that scores above the mean were rated Non-conventional struc- 
ture and scores below the mean were rated Conventional structure. The Cronbach's alpha for the scale in the present study was .78.

Process Measure. Cognitive process was measured using the Myers-Briggs Indicator (Myers, 1962). This is a well known measure of cognitive styles (cf. Henderson \& Nutt, 1980; Cowan, 1987; Kummerow \& Hirsch, 1986), and is based on Jung's (1924) theoretical network of personality functions. We utilized the Judging/Perceiving measure which describes a general overall preference either for making decisions and coming to a conclusion or delaying decisions and avoiding closure (Busche \& Gibbs, 1990).

Individuals who prefer a Conclusive (Judging) cognitive process are those who desire to make decisions and achieve closure. They operate as if things should be decided (Bushe \& Gibbs, 1990) and they show concern for planning and organizing activities. They are methodical and orderly. They tend to find meaning from previous experiences, plans and customs. They seek closure and finality. Decision makers who prefer the Nonconclusive (Perceiver) process are more spontaneous, flexible, open to new possibilities, reluctant to finalize and not rigid in their reliance on past experience. They avoid closure so as not to miss an important experience (Bushe \& Gibbs, 1990). The measure captures an individual's preference for making a decision (and not seeking more information) or delaying a decision (in order to seek out more information) as noted by Taylor (1984), Harrison (1981), Huber (1980) and MacCrimmon \& Wehrung (1986). The Cronbach's alpha for the measure in this study was .62. The correlation between the measures of the two cognitive dimensions was $-.17(\mathrm{p}<.10)$.

\section{Dependent Variables}

The dependent variables in the experiment were an interpretation of risk and decision outcome. First, subjects were asked to make an assessment in probability terms of how likely it would be for them to enter the joint venture (See Appendix A). A low probability estimate meant that a decision maker was not inclined to enter the joint venture, while a high probability estimate meant that a decision maker was more inclined to enter the joint venture. The mean response to this question (Probability) was $47.6, \mathrm{SD}=24.03$. In other words, on average, subjects reported that they required slightly less than a fifty/fifty chance of success to go it alone.

Subjects were then asked: "What is the likelihood you would reject YYY's offer?" and indicated their response on a five-point scale anchored by $1=$ reject; $2=$ lean toward rejecting; 3 =uncertain; $4=$ lean toward accepting and 5=accept. This response provided a second measure of decision outcome. Mean response to this question (Likelihood Reject) was 2.47, $\mathrm{SD}=1.42$.

Finally, subjects were asked about their interpretation of the risks involved in the situation: "Indicate the level of risk you believe is associated with rejecting YYY's offer". Subjects indicated their response on a five-point scale with the following anchors: $1=$ no risk; $2=$ some risk; $3=$ normal risk; $4=$ considerable risk and $5=$ too risky. Mean response to this question (Risk Level) was 2.70 , 
$\mathrm{SD}=.90$. Thus, consistent with the expected values built into the scenario, subjects on average reported that rejecting the joint venture had some risks.

\section{Results}

\section{Manipulation Checks}

Scenario based research captures reported intentions, not necessarily a decision maker's "real" actions. It is thus important to estimate how seriously the subjects approached the experimental task. So, after reading the decision scenario the subjects answered three questions that were intended to assess how seriously they viewed their roles in the experiment and how much responsibility they felt as decision makers. Subjects were asked how important the decision was ( $1=$ not important, $5=$ very important: mean response $=4.26, \mathrm{SD}=.76$ ); how responsible they felt for the decision ( $1=$ not at all responsible, $5=$ very responsible: mean response $=4.19, \mathrm{SD}=.73$ ), and where they felt the locus of success resided ( $1=$ out of my hands, $7=$ in my hands: mean response $=5.23, \mathrm{SD}=1.10$ ).

The results of these manipulation checks indicated that subjects viewed the problem as important they felt responsible for the decision and they felt that the opportunity for a successful outcome was in their hands. Based on the responses to these three questions, we concluded that the subjects had projected themselves into the scenario and took their decision making task seriously.

\section{Data Analysis}

Tables 1, 2 and 3 report the cell means and standard deviations for the dependent variables. Table 4 reports the results of $2 \times 2$ Analysis of Variance procedures used to test the hypotheses.

Table 1

Cell Means for Probability

(Standard Deviations in Parentheses)

\begin{tabular}{|c|c|c|c|}
\hline & & & \\
\hline & Nonconclusive & Conclusive & \\
\hline Conventional & $\begin{array}{c}68.2 \\
(18.7) \\
\text { Sage }\end{array}$ & $\begin{array}{c}46.8 \\
(23.7) \\
\text { Protector }\end{array}$ & $\begin{array}{c}54.6 \\
(24.1)\end{array}$ \\
\hline Non-conventional & $\begin{array}{c}44.2 \\
(24.3) \\
\text { Visionary }\end{array}$ & $\begin{array}{c}37.5 \\
(20.0) \\
\text { Maverick }\end{array}$ & $\begin{array}{c}40.8 \\
(22.0)\end{array}$ \\
\hline & $\begin{array}{c}55.1 \\
(24.8)\end{array}$ & $\begin{array}{c}42.5 \\
(42.5)\end{array}$ & $\begin{array}{c}47.6 \\
(24.0)\end{array}$ \\
\hline
\end{tabular}




\section{Table 2}

Cell Means for Risk Interpretation

(Standard Deviations in Parentheses)

\begin{tabular}{|c|c|c|c|}
\hline & & & \\
\hline & Nonconclusive & Conclusive & \\
\hline Conventional & $\begin{array}{l}3.2 \\
(.83) \\
\text { Sage }\end{array}$ & $\begin{array}{c}2.9 \\
(.91) \\
\text { Protector }\end{array}$ & $\begin{array}{c}3.0 \\
(.89)\end{array}$ \\
\hline Non-conventional & $\begin{array}{c}2.6 \\
(1.0) \\
\text { Visionary }\end{array}$ & $\begin{array}{c}2.3 \\
(.68) \\
\text { Maverick }\end{array}$ & $\begin{array}{c}2.4 \\
(.84)\end{array}$ \\
\hline & $\begin{array}{c}2.8 \\
(.99)\end{array}$ & $\begin{array}{c}2.6 \\
(.84)\end{array}$ & $\begin{array}{c}2.7 \\
(.90)\end{array}$ \\
\hline
\end{tabular}

The data in Table 2 support Hypothesis 1. Subjects with conventional cognitive structures reported perceiving more risk than those with non-conventional cognitive structures. The mean response for conventionals was 3.0 (SD .89) while the mean response for non-conventionals was 2.4 (SD .84) and these means are significantly different $(\mathrm{F}=13.57, \mathrm{p}<.001)$.

Table 3

Cell Means for Likely To Reject Offer

(Standard Deviations in Parentheses)

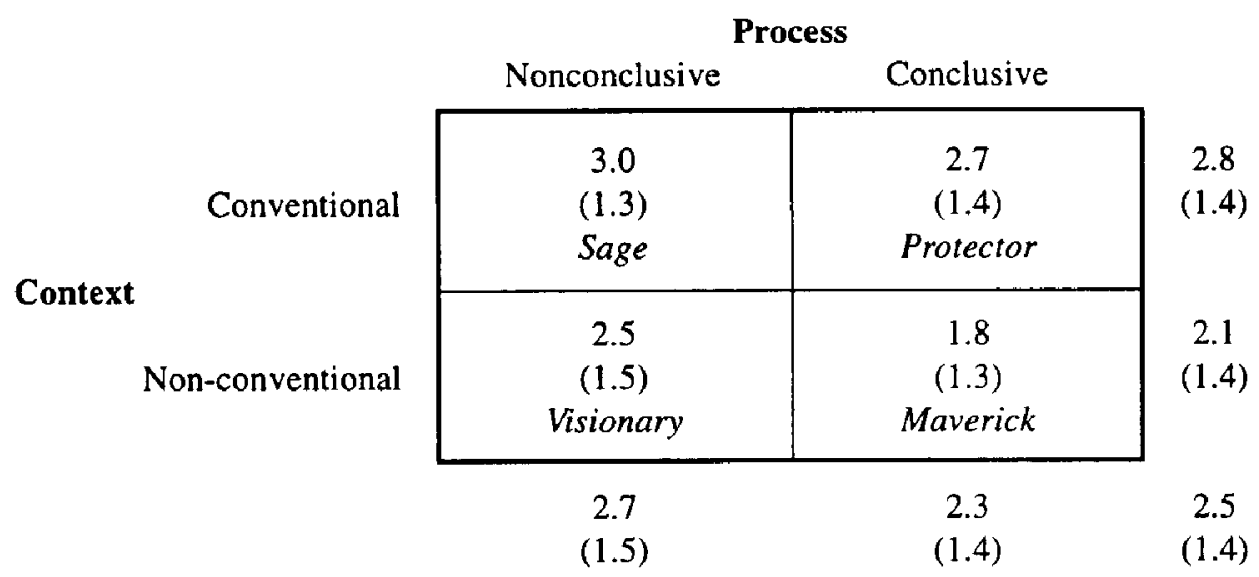


Table 4

Analyses of Cognitive Structure Preferences

\begin{tabular}{llrll}
\hline Dependent Variable & Independent Variable & $\mathrm{F}$ & $\mathrm{Pr}$ & $\mathrm{R}^{2}$ \\
\hline Probability & Full Model & 6.08 & .000 & .19 \\
& Context & 11.14 & .001 & \\
& Process & 7.90 & .006 & \\
& C x P & 2.15 & .14 & \\
\hline Risk Level & Full Model & 5.23 & .002 & .12 \\
& Context & 13.57 & .000 & \\
& Process & 2.89 & .09 & \\
& C x P & .10 & .75 & \\
\hline Likelihood Reject & Full Model & 4.27 & .007 & .10 \\
& Context & 7.74 & .006 & \\
& Process & 3.90 & .050 & \\
& C x P & .50 & .48 & \\
\hline
\end{tabular}

Data in Tables 1 and 3 support Hypothesis 2. Subjects with conventional cognitive structures were more risk averse. They required a higher probability of success to go it alone ( $54.6 \%$ vs. $40.8 \%$ ) and they reported leaning toward accepting the joint venture offer ( $2.8 \mathrm{vs}$. 2.1$)$. Both of these mean differences were statistically significant (see Table 4).

Data in Table 2 do not support Hypothesis 3. While the data were in the predicted direction, the differences in the means did not reach conventional levels of statistical significance.

Data in Tables 1 and 3 support Hypothesis 4. Subjects with nonconclusive cognitive structures were more inclined to accept the joint venture (take the risk averse option) ( $2.7 \mathrm{vs.} 2.3$ ) and also required a higher probability of success to go it alone $(55.1 \%$ vs. $42.5 \%)$. Both these mean differences were statistically significant (see Table 4).

Follow-up cell contrasts indicated that the Maverick structure was significantly more risk seeking than the Sage for each of the dependent variables. Moreover, the data in the tables showed a remarkably similar pattern in terms of perception and behavior. For each of the dependent variables the Sage was the most risk averse, the Protector second most risk averse, the Visionary second most risk seeking, and the Maverick the most risk seeking, although as noted the statistically significant difference was between the Maverick and Sage.

\section{Discussion}

In this paper we have helped contribute to a richer understanding of individual decision making in organizations by demonstrating the importance of one 
kind of individual difference: the individual's cognitive structure. We have suggested that decision makers tend to use one of four distinct types of cognitive structure, and that each type organizes information, interprets problems, and chooses in a distinct way as a result.

More specifically, we have suggested that cognitive structures differ on two dimensions: cognitive context and cognitive process. An individual may prefer a conventional context, referring retrospectively to historical practices for clues in dealing with current issues. Alternatively, individuals may prefer what is nonconventional; look outside current paradigms and traditions, and generally challenge accepted practices.

The cognitive process dimension, on the other hand, refers to the individual's preferences for using information either to make a decision (conclusive), or as a springboard for further information gathering (nonconclusive). The conclusive process is decisive, purposeful and exacting while the nonconclusive process is open, disorderly and possibly slow. While the conclusive process pushes the decision through to closure, the nonconclusive process delays decision making because of the desire to keep searching for more information.

The two dimensions combined yield four possible types: Protector (conventional, conclusive), Sage (conventional, nonconclusive), Visionary (nonconventional, nonconclusive) and Maverick (non-conventional, conclusive). The resulting types range from decision makers who are decisive and rely on history to guide decisions (Protector) to information gatherers who prefer information from traditional sources and engage in exhaustive yet delayed problem solving (Sage), to swift, decisive, innovators who move boldly (Maverick), to opportunity-seeking decision makers who are capable of charting new directions for an organization, yet who seem to love the search for new and interesting information (Visionaries). Our study shows that the four cognitive structures lead to different interpretations of problems and ultimately different choices.

This study has implications both for decision making in organizations and for decision making in groups. One implication is that the manager may be able to improve his/her own decision making by first understanding his/her own cognitive structure, and second, by becoming aware that individuals differ in their preferences for context and process. Though the manager may think that ability and experience can lead to objective and balanced decision making, our findings suggest that the choices an individual makes may be much a function of individual differences. Moreover, an organization's strategies may then also be a function of the cognitive structures of the top manager or top management team (Hambrick, 1984). For example, a powerful Protector COO may take his/her organization down the tried and true path dictated by years of organizational history. On the other hand, a top management team that is "stacked" with Visionaries may formulate new directions for the organization, but not have the ability to move as decisively as needed. 
In practical terms, decision making in organizations can be enhanced by the self aware manager who uses information about his/her own and others' preferences to construct decision making groups that, in balance, can make better decisions. Although future research would have to demonstrate the value of "balanced groups," it is nonetheless possible to logically infer how each of the four types provides a countervailing proficiency for what is lacking in the others. For example, the Protector will remind the group to look back and give proper respect to an organization's history, and will also move for efficient, orderly decisions; the Sage will prompt the team to delay in order to gather more information - new, useful information about the environment that can assist the group to gain richer insights and better ideas; the Visionary can unstick the group from rigid thinking, and even boldly take the group into exciting new territories; the Maverick can be the project champion who gets the job done once s/he is convinced of the best direction for the organization to take. The four types all together provide for a fast (but not too fast), decisive (but not at the expense of new, exciting data) balanced team. By being mindful of the countervailing forces in play when individuals with diverse cognitive structures work together, the manager can anticipate strengths and possible weaknesses of team decision efforts.

The issue of more cognitively diverse teams likely cannot proceed without conflict. In fact, our results show significant differences in the perception of problems and actual decision outcomes between Mavericks and Sages. These two categories represent cognitive polarities - both in terms of context and process. In decision making teams, the most conflict is likely to occur between people possessing these two structures because there is agreement neither on what context provides the most appropriate information, nor on how to decide. Disagreement over context means there is tension about what is important and disagreement over process means there is tension about how to decide.

Managers can greatly improve conflict laden processes by anticipating that conflict is increasingly part of organizational life and if managed effectively can lead to growth and innovation. Managers can achieve this insight if they understand that not everyone sees things the same way they do.

Multiple cognitive structures lead to multiple interpretations of the world, the organization, and its problems. The conflict that likely results from this cognitive diversity should not discourage managers. As Weick (1995) has suggested, it is only by unveiling the conflict that organizations can make sense of their environments. He warns managers not to see cognitive diversity as a weakness. "People often treat the existence of multiple interpretations as a symptom of a weak organizational culture rather than as an accurate barometer of turbulence outside the organization" (p. 101). The presence of multiple cognitive structures, managers' acknowledgment of this fact, and the ability to capitalize on those differences are likely to distinguish effective organizations from less effective ones. 


\section{References}

Anderson, C., \& Paine, F. (1975). Managerial perceptions and strategic behavior. Academy of Management Journal, 18, 811-823.

Bateman, T. S. \& Zeithaml, C.P. (1989). The psychological context of strategic decisions: A model and convergent experimental findings. Strategic Management Journal, 10 $59-74$.

Bushe, Gervase R. \& Gibbs, Barrie W. (1990). Predicting organization development consulting competence for the Myer-Briggs type indicator and stage of ego development. The Journal of Applied Behavioral Science, 26, 337-357.

Cowan, D. A. (1987). The effect of decision styles and levels of experience on executive's representation of different problem situations. Paper presented at National Decision Sciences meeting, Boston, MA.

Das, T. K., (1986). The Subjective Side of Strategy Making. New York: Praeger.

Eisenhardt, K. M. \& Zbaracki, M.J. (1992). Strategic decision making. Strategic Management Journal, 13, 17-37.

Gioia, D. \& Poole, P. (1984). Scripts in organizational behavior. Academy of Management Review, 9, 449-459.

Gioia, D. \& Mehra, A. (1996). A review of Weick's Sensemaking in Organizations. Academy of Management Review. 21, 1226-1230.

Hall, R. T. (1984). The natural logic of management policy making: Implications for the survival of an organization. Management Science. 30, 905-927.

Hambrick, D. \& Mason, P. (1984). Upper echelons: The organization as reflection of its top managers. The Academy of Management Review, 9, 193-206.

Harrison, E. F. (1981). The Managerial Decision-making Process. (2nd ed.). Houghton Mifflin Company: Boston.

Henderson, J. C. \& Nutt, P. C. (1980). The influence of decision style on decision making behavior. Management Science, 26, 371-386.

Hogarth, R. M. (1980). Judgment and Choice. John Wiley \& Sons: New York.

Huber, G. (1980). Managerial Decision Making. Scott, Foresman and Company: Glenview, IL. 
Ireland, R. D., Hitt, M. A., Bettis, R. A. \& de Porras, D. A. (1987). Strategy formulation processes: Differences in perceptions of strength and weakness indicators and environmental uncertainty by managerial level. Strategic Management Journal. 8, 469 485.

Janis, I. L. (1982). Groupthink: Psychological studies of policy decisions and issues (2nd ed). Houghton, Miflin Co., Boston.

Jung, C. (1924). Psychological Types. Harcourt Brace: New York.

Keller, R. T. \& Holland, W. E. (1978a). Individual characteristics of innovativeness and communication in research and development organizations. Journal of Applied Psychology, 63, 759-762.

Keller, R. T. \& Holland, W. E. (1978b). A cross validation study of the Kirton Adaption Innovation Inventory in three research and development organizations. Applied Psychological Measurement. 2, 563-570.

Keller, R. T. \& Holland, W. E. (1979). Toward a selection battery for research and development of professional employees. IEEE Transactions on Engineering Management. 26, 90-93.

Kiesler, S. \& Sproull, L. (1982). Management response to changing environments: Perspectives on problem sensing from social cognition. Administrative Science Quarterly. 27, 548-570.

Kirton, M. (1976). Adaptors and innovators: A description and measure. Joumal of Applied Psychology, 61, 622-629.

Kummerow, W. J. \& Hirsch, S. K. (1986). Introduction to type in organizational consulting settings. Consulting Psychologists Press, Inc.: Palo Alto, CA.

MacCrimmon, K. R. \& Wehrung, D. A. (1986). Taking risks: the management of uncertainty. The Free Press: New York.

March, J. G. (1981). Decision making perspectives: Decisions in organizations and theories of choice. in Van de Ven, A. H. \& Joyce, W. F. (Ed's) Perspectives on Organization Design \& Behavior. New York: John Wiley \& Sons.

Mitchell, T., Rediker, K., \& Beach, L. Image theory and organizational decision making. Sims, H. \& Gioia, D. (Ed's) The Thinking Organization. San Francisco: Jossey-Bass.

Myers, I. (1962). The Myers Briggs Type Indicator. Consulting Psychological Press: Palo Alto, CA. 
Nystrom, P. C. \& Starbuck, W. H. (1984). To avoid organizational crises, unlearn. Organizational Dynamics. 4, 53-65.

Russo, J. E. \& Schoemaker, P. J. H. (1990). Decision traps: The ten barriers to brilliant decision-making and how to overcome them. Simon \& Schuster: New York.

Schoemaker, P. J. H. (1993). Strategic decisions in organizations: Rational and behavioral views. Journal of Management Studies, 107-130.

Simon, H. A. (1978). Rationality as process and product of thought. American Economic Review, 68, 1-16.

Taylor, Ronald. (1984). Behavioral Decision Making. Scott, Foresman and Company: Glenview, IL.

Tversky, A. \& Kahneman, D. (1974). Judgment under uncertainty: Heuristics and biases. Science. $185,1124-1131$.

Weick, K. E., (1979). The social psychology of organizing. Reading, MA: Addison-Wesley.

Weick, K. E., (1995). Sensemaking in organizations. Thousand Oaks, CA.; Sage Publications, Inc.

\section{Appendix A}

\section{Scenario}

Note: When respondents read this scenario they read the real names of companies and products. Those names and products have been disguised here (placed in quotes) for reasons of confidentiality.

You are the Vice-President and G.M. of "XXX/xxx". The Manager of Product Planning has just requested an emergency meeting to discuss a proposal by "YYY" Corporation, your most aggressive competitor.

It seems that "YYY" has been re-evaluating the "AAA" market and feels that with the advances in "XXX" solids modelling capability, "XXX" could potentially capture a large share of this market. Ironically "YYY" has also targeted this market, but believes that together, "XXX" and "YYY" could be more successful via cooperation than through the destructive effects of market entry by two big competitors. "XXX" attorneys have already looked at the anti-trust implications of such a joint venture and there appears to be no legal problems. "YYY" seems determined to enter the market with or without "XXX", so if "XXX" refuses to go with "YYY" into this market, "XXX" can plan on aggressive competition. 
Product planning has made some "best guess" estimates as to the bottom-line odds and payoffs of "XXX" going it alone or in combination with "YYY." They feel that if "XXX" goes it alone and captures a large market share, "XXX" could realize an after-tax ROI of $22 \%$, while capturing a small market share would yield approximately $10 \%$ ROI. They estimate the chances of "XXX" attaining a large market share on its own to be 1 in 3 , or $33 \%$. If "XXX" teams up with "YYY" on the terms they propose, it is virtually assured "XXX" would achieve an after-tax ROI of $14 \%$ with the same total investment.

Either way, the investment seems attractive. "YYY" has requested a yes or no answer in two weeks. As VP of " $x x x "$ you must decide the course to pursue.

If the chances of "XXX" achieving a large market share were 99 out of 100 you would probably recommend going it alone. Conversely, if the chances of achieving a desirably large market share were only 1 in 100 you would probably recommend going in jointly with "YYY." As "XXX's" chances of achieving the desired market share were increased, there would be a point at which you would recommend going it alone as opposed to going with the joint venture; that is, what is the lowest chance of "XXX" being successful that would prompt you to go it alone versus the joint venture?

$\%$

For the questions/statements below circle the number that comes closest to describing how you feel.

A. What is the likelihood you would reject "YYY's" offer?
Reject
Lean toward
2
3
4
Accept

B. Indicate the level of risk you believe is associated with rejecting "YYY's" offer.
No Risk
Some Risk
Normal Risk
Considerable Risk
4
Too Risky
1 2 3
5

C. How responsible do you feel for the decision to undertake the project with or without "YYY"?

Not Very Responsible

1

2
Neutral

3
Very Responsible

4

5

D. How important do you think this decision is?

Not Very

Important

1
2
Neutral

3
4
Very
Important
5

E. Responsibility for the success of the project...

Is out of my Control

Equally Shared

4

5

6

Is in my Hands 
Dr. Dennis Duchon is an Associate Professor of Management at the University of Texas at San Antonio. He received his Ph.D. from the University of Houston. His research interests include decision making in organizations, work motivation, and leadership. He has published in the Journal of Applied Psychology, the Journal of Management, Organizational Behavior and Decision Processes, and Decision Sciences, among others.

Dr. Donde P. Ashmos is an Associate Professor of Management at The University of Texas at San Antonio. She received her Ph.D. in Strategic Management from The University of Texas at Austin. Dr. Ashmos' publications have appeared in The Academy of Management Review, Organizational Behavior and Decision Processes, Journal of Applied Behavioral Science, Interfaces, Health Services Research and Human Resource Management, among others.

Dr. Maria Nathan is an Assistant Professor of Management at the University of Texas at San Antonio. She received her Ph.D. in Management from the University of Southern California in 1992, and has also taught at the University of California, Los Angeles, and the University of Wisconsin-Madison. Her research is in strategic decision making, crisis learning, and nonprofit governance, and she has published in the Academy of Management Review, the Academy of Management Executive, the Journal of Applied Behavioral Science, among others. 